\title{
A Machine Learning Approach to Analyzing Corruption in Local Public Finances
}

\section{Working Paper}

\section{Author(s):}

Ash, Elliott; Galletta, Sergio; Giommoni, Tommaso

Publication date:

2020-04

Permanent link:

https://doi.org/10.3929/ethz-b-000414608

Rights / license:

In Copyright - Non-Commercial Use Permitted

Originally published in:

Center for Law \& Economics Working Paper Series 06/2020 


\title{
$\boldsymbol{G H}$ zürich
}

\section{Center for Law \& Economics Working Paper Series}

Number 06/2020

\section{A Machine Learning Approach to Analyzing Corruption in Local Public Finances}

\author{
Elliott Ash \\ Sergio Galletta \\ Tommaso Giommoni
}




\title{
A Machine Learning Approach to Analyzing Corruption in Local Public Finances ${ }^{\star}$
}

\author{
Elliott Ash ${ }^{1}$, Sergio Galletta ${ }^{1,2}$, Tommaso Giommoni ${ }^{1}$ \\ ${ }^{1}$ ETH Zürich \\ ${ }^{2}$ University of Bergamo
}

\begin{abstract}
This paper applies machine learning tools to detect local-government corruption using budget accounts data. In the context of Brazilian municipalities, we have gold-truth labels for corruption from a set of federally mandated audits (assigned randomly by lottery) for the years 2003 to 2010. Our tree-based gradient-boosted classifier can predict the presence of corruption in held-out test data, consistent with an expected link between corruption and budget composition. The trained model, when applied to new data, provides a synthetic measure of corruption which can be used for new empirical analysis. We confirm the empirical usefulness of this measure by replicating, and extending, some previous empirical evidence on corruption issues in Brazil. In particular, we exploit the longitudinal nature of our data to produce new evidence on the dynamic effects of audits on corruption, including spillover effects on neighboring municipalities.
\end{abstract}

JEL Classification: D73, E62, K14, K42.

Keywords: machine learning, corruption, audits, local public finance.

${ }^{\star}$ We benefited from comments by participants at seminars at the University of St. Gallen, ETH Zürich, University of Zürich and the "Advances in Economics Winter Symposium" (Bergamo). We are grateful to Francisco Cavalcanti for sharing essential data for conducting the analysis. David Cai and Matteo Pinna provided excellent research assistance. This version: April 2020 (First version: April 2020)

Email addresses: ashe@ethz.ch (Elliott Ash), sergio.galletta@unibg.it (Sergio Galletta), giommoni@kof.ethz.ch (Tommaso Giommoni) 
Corruption is an insidious plague that has a wide range of corrosive effects on societies. It undermines democracy and the rule of law, leads to violations of human rights, distorts markets, erodes the quality of life and allows organized crime, terrorism and other threats to human security to flourish. This evil phenomenon is found in all countries-big and small, rich and poor-but it is in the developing world that its effects are most destructive. Corruption hurts the poor disproportionately by diverting funds intended for development, undermining a Government's ability to provide basic services, feeding inequality and injustice and discouraging foreign aid and investment. Corruption is a key element in economic underperformance and a major obstacle to poverty alleviation and development.

- Kofi A. Annan

\section{Introduction}

A large body of anecdotal and empirical evidence speaks to the deep and negative impacts of corruption. Kofi Annan's words aside, social scientists have demonstrated that foul play by government actors does real harm to the average citizen. These harms lead to responses in politics and political participation (Ferraz and Finan, 2008; Chong et al., 2015), undermine trust toward institutions (Morris and Klesner, 2010), and have additional side effects on the economy (Lagaras et al., 2017).

Accordingly, governance researchers are searching for solutions to combat corruption. Broadly speaking, there are two central approaches. First, electoral incentives play a crucial role in discouraging misbehavior by officials (Ferraz and Finan, 2008; Winters and Weitz-Shapiro, 2013). Second, an effective judicial system to prosecute offenders and enforce the law may be necessary to deter corrupt actions (Becker, 1968; Djankov et al., 2003). Yet, one of the main problems in evaluating anti-corruption policies is the limited information on detected corruption. Although several countries have introduced monitoring programs to detect wrongdoing, these are typically limited to a relatively small subset of public officials, due in part to the high cost of running such programs.

The problem of undetected corruption is important for both policymakers and for social scientists. Thus, the first aim of this paper is to overcome this data limitation by adopting tools from machine learning to extend datasets on corruption. Second, we assess the quality of such methods by replicating and extending previous results on local corruption. 
The core of our idea is to exploit the fact that corruption, by its nature, is related to how politicians and public officials decide to allocate public resources (Mauro, 1998). This idea is especially relevant in our institutional context of Brazilian municipalities, as discussed further below. Specifically, we use the link between corruption and the composition of government budgets to create an index measuring the predicted probability of official misbehavior.

Our analysis focuses on corruption in local government in Brazil. We start with a ground-truth measure of detected corruption, identified and quantified by professional government auditors (Ferraz and Finan, 2008; Brollo et al., 2013). We link this corruption outcome with a rich historical account of local public budgets (with information on 797 fiscal categories).

We use machine learning to predict corruption from the features of the budget accounts. We implement a gradient boosted classifier consisting of an ensemble of decision trees, typically used to identify patterns in high-dimensional datasets. Using only municipal budget characteristics, the classifier can detect the existence and predict the intensity of corruption with high accuracy in held-out (unseen) data. In the best model, we get an accuracy of $76 \%$ and an AUC of 0.834 , far better than guessing the modal category. We also show that the model accurately ranks municipalities by probability of corruption and can reproduce the distribution of corruption in the test set. Finally, we use model explanation techniques to show that it identifies intuitive factors in the budget that are anecdotally related to corruption.

To demonstrate the empirical applicability of the method, we use the out-of-sample prediction as a synthetic measure of corruption to replicate previous causal results on local corruption in Brazil. First, we replicate the result from Brollo et al. (2013) that a revenue windfall, based on population thresholds, increases corruption. In particular, we can show this result in an untouched sample of municipalities that were never audited by the Brazilian authorities. Coefficient magnitudes are, then, comparable with those obtained with true data by Brollo et al. (2013).

As a second empirical application, we use our measure in an event study framework to show that an audit causally reduces corruption in fiscal accounts over the subsequent years, with an average drop of around $5 \%$ in the probability of malfeasance. Moreover, the effect is especially large for audits that did find corruption, with an average decline of around $20 \%$. In comparison, there is no effect for audits that did not find corruption.

Finally, we look at the spillover effects of audits on fiscal corruption in neighboring 
municipalities. We do find such spillover effects: when an audit finds corruption, fiscal corruption in neighboring municipalities goes down in subsequent years. Audits that do not find corruption do not have a spillover effect.

All of these effects are persistent, lasting at least five years after the audit. The spillover effects are especially interesting as they can be interpreted as a behavioral response (since neighbors are no more likely to be audited subsequently). These results provide new evidence about the effectiveness of audits as anti-corruption policies.

Our findings are related to several literatures in economics. First, our paper contributes to the literature studying the relation between corruption and public finance. Many studies emphasize the connection between governmental transfers and public corruption: Brollo et al. (2013) focus on the Brazilian setting, while De Angelis et al. (2018) study the impact of European funds on rent-seeking activity. Another set of papers analyze the extent to which corruption originates from public spending (Hessami, 2014; Cheol and Mikesell, 2018), and there is evidence that policies that constrain public expenditure may reduce corruption (Daniele and Giommoni, 2020). Further, other works attend to the link between public procurement and rent-seeking (Conley and Decarolis, 2016; Coviello and Gagliarducci, 2017). Our results confirm the deep link between public financing and corruption with a focus on the entire budget, instead of single elements, to explain malfeasance. Our approach has the advantage of being general, making it possible to capture the complementary aspects within the budget.

In particular, our study contributes to a growing body of work on corruption and politics in Brazil. For instance, Ferraz and Finan (2008) show that the disclosure of scandals reduces vote shares for the incumbent. Cavalcanti et al. (2018) emphasize that exposing corrupted incumbents affects the quality of candidates selected by their party to run in the following election. In Ferraz and Finan (2011), electoral accountability affects corruption: when mayors are up for reelection, rent-seeking is significantly lower.

Next, we add to the existing evidence on the efficacy of auditing programs on corruption in developing countries. Olken (2007) set up an RCT with villages in Indonesia and find that the introduction of the auditing scheme decreased corruption. Bobonis et al. (2016), studying municipalities from Puerto Rico, show that audits effectively reduce corruption and rent-seeking activities, by enhancing electoral accountability in the short run, but these effects do not last. Zamboni and Litschig (2018) show, in the Brazilian context, that increasing the probability of a municipality of being audited was already effective in reducing corruption. Avis et al. (2018) also study the Brazilian case and find 
that the implementation of an audit in a specific city reduces future corruption levels in that city. Our event study analysis confirms the latter results, and we are the first to show the dynamics of this effect. Moreover, we find that the effect is particularly strong in cities where corruption is actually detected.

Methodologically, our study adds to the emerging literature in economics and political science applying machine learning techniques to overcome limitations of standard datasets. For instance, Draca and Schwarz (2019) use Latent Dirichlet Allocation (an unsupervised machine learning algorithm) to measure ideological dimensions of citizens from political survey data. Bandiera et al. (2020) use a similar method to detect CEO behavioral types from their work activity records. Like these papers, we use machine learning to measure an interesting dimension from high-dimensional data. Our innovation is to use supervised learning (rather than unsupervised learning) to construct these measurements. Relatedly, several papers in political economy have used supervised learning to extract measures of partisanship from text (Gentzkow and Shapiro, 2010; Ash et al., 2017; Gentzkow et al., 2019).

There are also some existing applications of machine learning methods focused on corruption. ${ }^{1}$ Nevertheless, none of them uses the power of the predictions to create new measure of corruption. The closest to our framework is Colonnelli et al. (2019), who also predict the results of corruption audits in Brazilian municipalities but focusing on non-budget variables (private sector activity, financial development, and human capital measures). Besides our focus on fiscal factors, the main difference in our paper is to use the measure of corruption for an empirical analysis. Colonnelli et al. (2019) (and related papers) limit their analysis to the prediction exercise.

Finally, outside of public economics, our findings are relevant to policy design - and in particular, the use of machine learning techniques for solving policy problems (Kleinberg et al., 2015; Athey, 2018). We show that these techniques can support government efforts to detect municipalities with suspicious public budgets that are more likely to be at risk of corruption. While these metrics do not prove whether a municipality is corrupt, they could point to places where further investigation is warranted. Thus ML could contribute to more effective and efficient anti-corruption policies.

\footnotetext{
${ }^{1}$ For instance, López-Iturriaga and Sanz (2018) predict the presence of a corruption case each year in 52 Spanish provinces. More at the micro level, Gallego et al. (2018) predict corruption investigations associated with a sample of 2 million public contracts in Colombia.
} 
The paper is organized as follows. In Section 2 we present the institutional setting and the data. In Section 3 we describe the prediction procedures and the results. In Section 4 we provide the estimation strategy and the results of the empirical applications, while Section 5 concludes.

\section{Institutional Background and Data Sources}

\subsection{Local Government and Budgets}

Our analysis focuses on Brazilian local jurisdictions. Brazil is a decentralized country composed of 26 states and around 5500 municipalities. At the municipal level, the main political authorities are the mayor (prefeito) and the city council (Câmara de Vereadores), which are directly elected by citizens every 4 years. Starting from the 1980s, local governments have enjoyed substantial autonomy in public budgeting decisions. They have primary responsibility for the provision of health and education services as well as municipal transportation and infrastructure. For the main part, these services are funded by upper-level jurisdictions via intergovernmental transfers. Yet, the mayor has autonomy in setting the tax rate for important property local taxes, e.g., taxes on buildings and lands (Imposto sobre a Propriedade Predial e Territorial Urbana - IPTU), as well as sales tax on services (Imposto sobre Serviços).

We collected the annual budget of all Brazilian municipalities for 2001 through 2012. Unlike most of the existing public finance literature, we gather detailed information about the categories of expenditure, revenue, as well as active (assets) and passive (liabilities) positions. These data are publicly available in the Finance Ministry's online database. ${ }^{2}$ In this period the budgets were composed of a large number of different categories for each section. In total we have 797 distinct variables.

Appendix Table A.1 reports the number of categories for each sections of the balance sheet for each year of data. Overall, there is an increasing level of details about the use and sources of revenue of local governments as the budget adapts to changes in the legislation. This also implies that there is some missingness, as not all categories are reported for each year and/or each municipality. ${ }^{3}$ The highest number of categories is reported for the year 2012 the lowest in year 2001. Expenditure is the section of the

\footnotetext{
${ }^{2}$ http://www.tesouro.fazenda.gov.br/pt_PT/contas-anuais

${ }^{3}$ For the main results, we deal with this by imputing the mean and also adding an indicator variable for missingness.
} 
budget that includes the highest number of categories, while passive is the one with the lowest.

\subsection{Anti-corruption policy in Brazil}

In 2003 the Brazilian government, led by Luís Inácio Lula da Silva, introduced new policies to reduce corruption and in particular misuse of federally transferred funds by local authorities. The foundation of the reform was a lottery, in which municipalities are randomly selected to be audited by officials from the the public agency Controladoria Geral da União (CGU). In each round, between 50 and 60 municipalities are selected, excluding municipalities with more than 500,000 inhabitants. Lotteries are run independently for each state, so the probability for a municipality to be selected in a given year varies by state.

Every selected municipality is visited by 10 to 15 auditors. Their inspections focus on a list of randomly selected items provided by the CGU from the sample of federal transfers the municipality received in the previous 3-4 years. They usually spend a couple of weeks in municipal offices collecting information to identify potential mismanagement in the use of public funds. The auditors summarized the presence of irregularities in reports that are made available to the public a few months later. These reports provide detailed information that can be used to create measures of municipal-level corruption (Ferraz and Finan, 2008; Brollo et al., 2013; Zamboni and Litschig, 2018).

For our analysis we use the corruption measures provided by Brollo et al. (2013). ${ }^{4}$ These data include several measures of corruption for all 1,481 municipalities audited in the first 29 lotteries of the anti-corruption program (i.e., audits that took place from 2003 to 2010). Specifically, they compute the share of corrupted resources by municipalityterm (i.e., the ratio between the total amount of funds involved in the detected violation and the total amount audited). Our analysis focuses on a binary variable identifying the presence of what the authors call narrow corruption, which is restricted to severe irregularities such as illegal procurement, fraud, favoritism, and over-invoicing. ${ }^{5}$ On average, $42 \%$ of municipalities at their first audit are found to have some level of corruption.

Finally, we link the corruption data at the municipality-term level with the local

\footnotetext{
${ }^{4}$ We are collecting also the data used by Avis et al. (2018) to further validate and extend our analysis.

${ }^{5}$ In addition, they define a measure of broad corruption, which also includes inconsistencies that could be linked to government mismanagement, but not intentional misuse. $76 \%$ of audit municipalities are found to have positive levels of broad corruption.
} 
budgets data at the municipality-year level. Therefore, corruption is constant within a given term for each audited municipality.

\section{Predicting Corruption from Budget Data}

\subsection{Machine Learning Approach}

For the prediction task we use a gradient boosted classifier (Friedman, 2001). ${ }^{6}$ Gradient boosting models consist of an ensemble of decision trees that "vote" on the predicted outcome. Gradient boosted machines gradually add additional layers of trees to fit the residuals of the first layers. This approach tends to improve out-of-sample performance compared to other ensemble methods, such us random forest which instead grows trees in parallel.

Before performing the predictions, we pre-process the data following these steps: 1) standardize the features using a quantile transformation (setting output distribution to normal); 2) impute in place of missing values the mean of the observed value for each variable; 3) for each budget item, create a new variable to identify when there is a missing value.

In preparation for model training, we split the sample of audited municipalities into a train (80\%) and test (20\%) set. ${ }^{7}$ We tuned the hyperparameters in the training set using five-fold cross-validation. We then took the tuned model to get performance metrics in the test set.

\subsection{Model Performance}

Table 1 (Panel A) shows the accuracy metrics of our machine learning models. Overall, the classifiers give substantial lift to predicting corruption in the held-out test data. The model reaches the best performance when including both municipal population size and missing value dummies. The test set accuracy is between 0.740 and 0.764 depending on the four models used. The AUC-ROC is between 0.793 and 0.834 , while F1 is between 0.663 and 0.687 . To stress the importance of using machine learning models when dealing with prediction tasks we report in the last column of Table 1 (Panel A) the performance of an ordinary least squares baseline. Indeed, each of the gradient boosting models is superior to OLS, which obtains a test-set accuracy of 0.594 , an AUC-ROC of

\footnotetext{
${ }^{6}$ Specifically, we use the python package xgboost (Chen and Guestrin, 2016).

${ }^{7}$ We limit analysis to first audits (when municipalities were randomly audited twice or more).
} 
Table 1: Machine Learning Metrics for Predicting Corruption in Held-Out Test Data

Panel A. Prediction performance

\begin{tabular}{c} 
Gradient Boosting \\
\hline Standard + Pop. $\begin{array}{c}\text { Missing } \\
\text { dummies }\end{array}$ missing dummies
\end{tabular}

(1)

$(2)$

(3)

(4)

\begin{tabular}{llllll}
\hline Accuracy & 0.750 & 0.761 & 0.740 & 0.764 & 0.594 \\
AUC-ROC & 0.814 & 0.824 & 0.793 & 0.834 & 0.562 \\
F1 & 0.665 & 0.685 & 0.663 & 0.687 & 0.413 \\
\hline
\end{tabular}

Panel B. Confusion Matrices

$\frac{\text { Standard }}{\text { Prediction }} \frac{+ \text { Pop. \& Missing Dummies }}{\text { Prediction }}$

Truth Not Corrupt Corrupt $\quad$ Not Corrupt Corrupt

$\begin{array}{lllll}\text { Not Corrupt } & 607 & 107 & 614 & 100\end{array}$

\begin{tabular}{lll|ll} 
Corrupt & 196 & 302 & 185 & 313
\end{tabular}

Notes: Panel A provides prediction performance for the four different specifications used with the gradient boosting model and OLS. Panel B shows the confusion matrices for the model with only standardized features and the model that also includes population and missing variable identifiers. 
Figure 1: Joint Distribution of True Corruption Rate vs. Predicted Probability of Corruption

(a) Standard

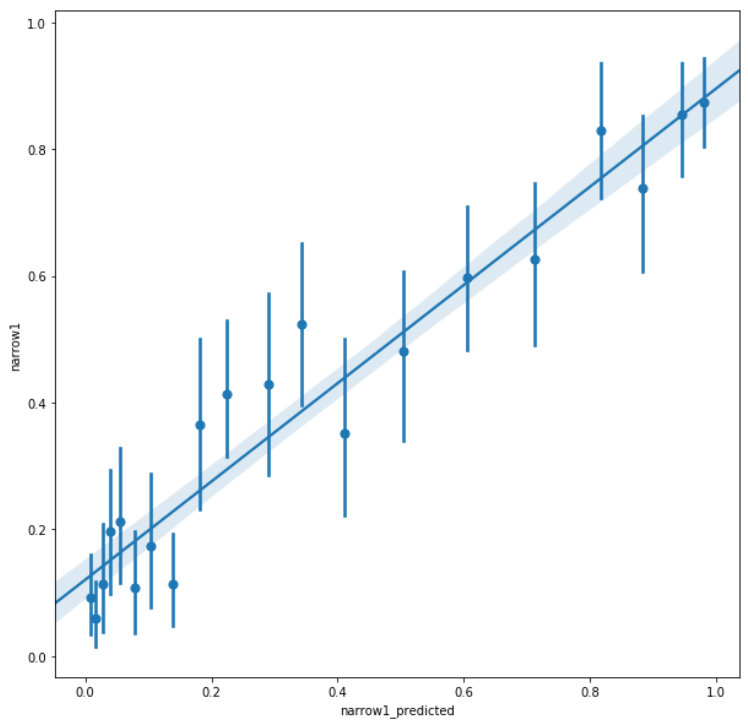

(b) + Pop. \& missing dummies

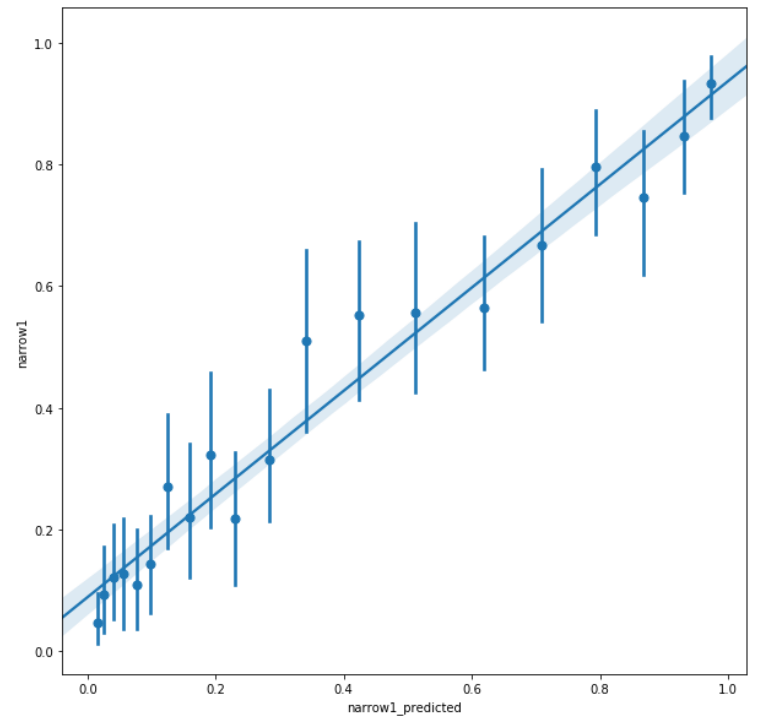

Notes: Binscatter diagrams of average true corruption (vertical axis) against binned predicted corruption (horizontal axis).

0.56, and an F1 of 0.413. Another way to think about these results is to compare the accuracy rates achieved if one would assign to the whole sample the modal category. In other words, if no-corrupted is assigned to the whole sample the accuracy rate would be 0.58 , which is similar to the accuracy from the OLS predictions. Table 1 (Panel B) shows the confusion matrix in the test sample to illustrate precision and recall. ${ }^{8}$

We can also see that the prediction models provide an effective ranking of municipalities by expected corruption. Figure 1 shows binscatter diagrams of true corruption (vertical axis) against our model predictions (horizontal axis) in the test set. For each model specification, the trend/ranking of predictions matches very well the trend/ranking of the true labels.

\subsection{Interpreting the Predictions}

Our implementation of gradient boosting includes a feature importance ranking. The most and least important features are listed in Table 2. On this metric, each feature is scored based on the number of times it appears in one of the model's constituent

\footnotetext{
${ }^{8}$ Confusion matrix for the OLS predictions are reported in Appendix Table A.2.
} 
Table 2: Importance of Budget Features for Corruption Prediction

\begin{tabular}{|c|c|c|c|c|c|}
\hline \multicolumn{3}{|c|}{ Most important } & \multicolumn{3}{|c|}{ Least important } \\
\hline Category & Macro Category & Weight & Category & Macro Category & Weight \\
\hline Assets & Assets & 330 & Royalties oil production (from FG) & Revenue & 0.2 \\
\hline Financial assets & Assets & 182 & Animal health defense & Expenditure & 0.2 \\
\hline Population & & 142.6 & Expenditure judicial decision & Expenditure & 0.2 \\
\hline Cash & Assets & 116.4 & Transf. agreement & Revenue & 0.2 \\
\hline Spending in agriculture & Expenditure & 94.8 & Participation in firms & Assets & 0.2 \\
\hline Property tax on rural land & Revenue & 89.6 & Transf. from private inst. (current) & Revenue & 0.2 \\
\hline Bank deposit & Assets & 85.4 & Transf. from private inst. (capital) & Revenue & 0.2 \\
\hline Motor vehicle property tax (from FG) & Revenue & 72.8 & Transf. for personnel to municipalities & Revenue & 0.2 \\
\hline Transf. of ownership tax & Revenue & 72 & Transf. for environment (capital) & Revenue & 0.2 \\
\hline Spending in transportation & Expenditure & 72 & Other expenditure in housing & Expenditure & 0.2 \\
\hline Outstanding loan credit & Assets & 69.4 & Allowance for loan losses & Assets & 0.2 \\
\hline Tax on industrialized products & Revenue & 69 & Short terms security & Assets & 0.2 \\
\hline Property tax on land/buildings & Revenue & 68 & Other expenditure in energy & Expenditure & 0.2 \\
\hline Liquid assets & Assets & 67.8 & Transf. for personnel to public sector & Revenue & 0.2 \\
\hline Civil servant per diems & Expenditure & 67.4 & Other financial investments & Expenditure & 0.2 \\
\hline Spending for legislative procedure & Expenditure & 65 & Other services & Expenditure & 0.2 \\
\hline Taxes & Revenue & 64.4 & Advertising & Expenditure & 0.2 \\
\hline Budget deficit & & 63 & Transf. for elementary school & Revenue & 0.2 \\
\hline Non financial current asset & Assets & 60.6 & Other expenditure military personnel & Revenue & 0.2 \\
\hline Capital expenditure & Expenditure & 60 & Other transf. agreement & Revenue & 0.2 \\
\hline
\end{tabular}

the ensemble classifier.

trees. This provides a proxy for how often the feature is used, capturing rich non-linear relations between features. These features are pivotal in the sense that, if they were left out, the model's predictions would become less accurate.

Beside a municipality's population size, the most relevant category comprises municipal assets. Particularly, the classifier points to current financial assets in the form of liquid assets, such as cash and bank deposits, financial investments, and outstanding loan credit. Other non-financial assets also play a role in predicting corruption.

After assets, the most frequent categories identified as relevant to corruption are those related to expenditures and revenues. We see corruption-related spending in support of the agricultural sector, of the legislative actions of the local government, as well as the provision of public services in transportation. Consistent with anecdotal evidence and the literature (see, for example, Tanzi and Davoodi, 1998), capital expenditures are also identified. More specific signals come from the arbitrary use of public funds in categories which perhaps are more difficult to monitor, for instance, civil servant per diems.

Taxes are important as well. The model is especially attending to different types of property taxes. These include property tax on rural land, on land/buildings, and on transfer of ownership. Finally, the budget deficit matters.

The list of least important features is of a very different character. It is a miscellaneous set of mostly minor features of the budget. They do not have an important role 
Figure 2: Model-Predicted Feature Importance and Mentions in Audit Report Texts

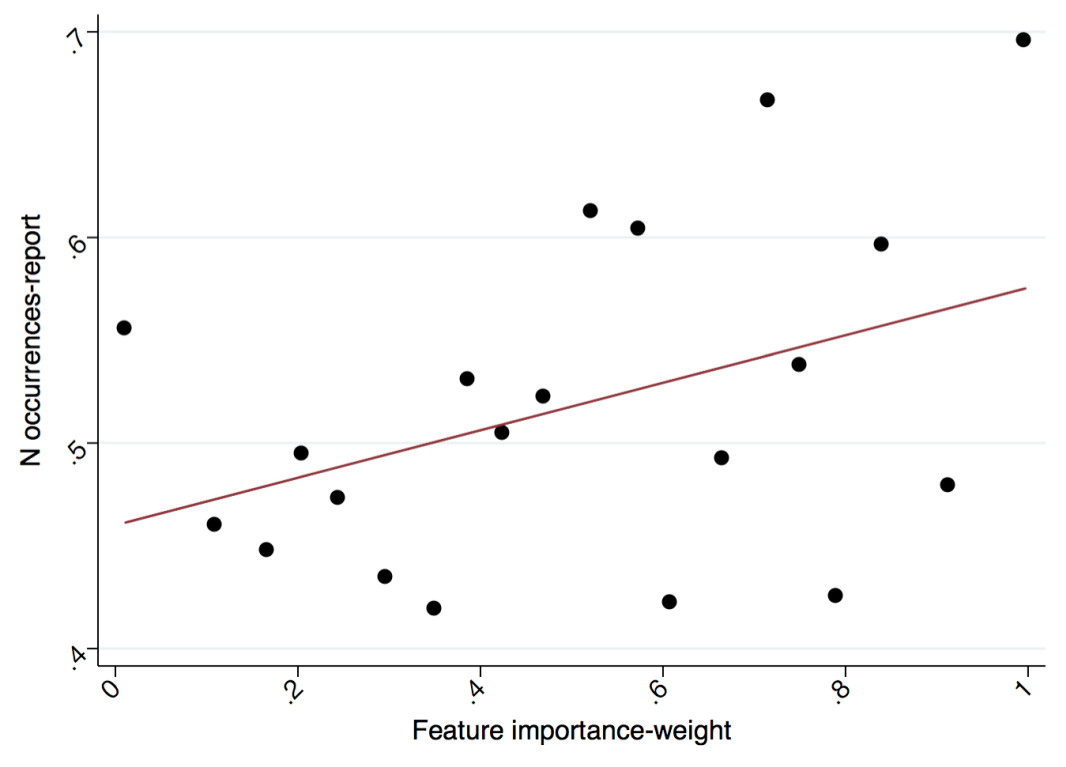

Notes: Binscatter diagram for frequency that a budget feature appears in the municipal audit reports (vertical axis) against binned feature importance weights for each feature (horizontal axis).

in local public finance.

To assess our feature importance weights quantitatively, we further compare our results to what is written in the audit reports. We downloaded the municipal audit reports, available from the agency web site. After converting the PDFs to text and cleaning the language we also counted the mentions of different budget features in the reports. In Figure 2, the percentile ranking of these mentions is plotted against the percentile rank of the classifier feature importance weights. We can see a clear positive relationship which is statistically significant. This means that our classifier, trained on the budget accounts with just corruption labels, identifies as important the same budget features that tend to be mentioned in the audit report documents.

These feature importance scores provide some helpful information about how our corruption prediction classifier is working. The corruption-related features are somewhat intuitive based on the institutional context, and they are mentioned more often in the municipal audit reports. This supports the view that we are measuring activities related to corruption, rather than other budget factors that may be correlated. 
Figure 3: The Geography of (Predicted) Corruption

(a) Actual Corruption

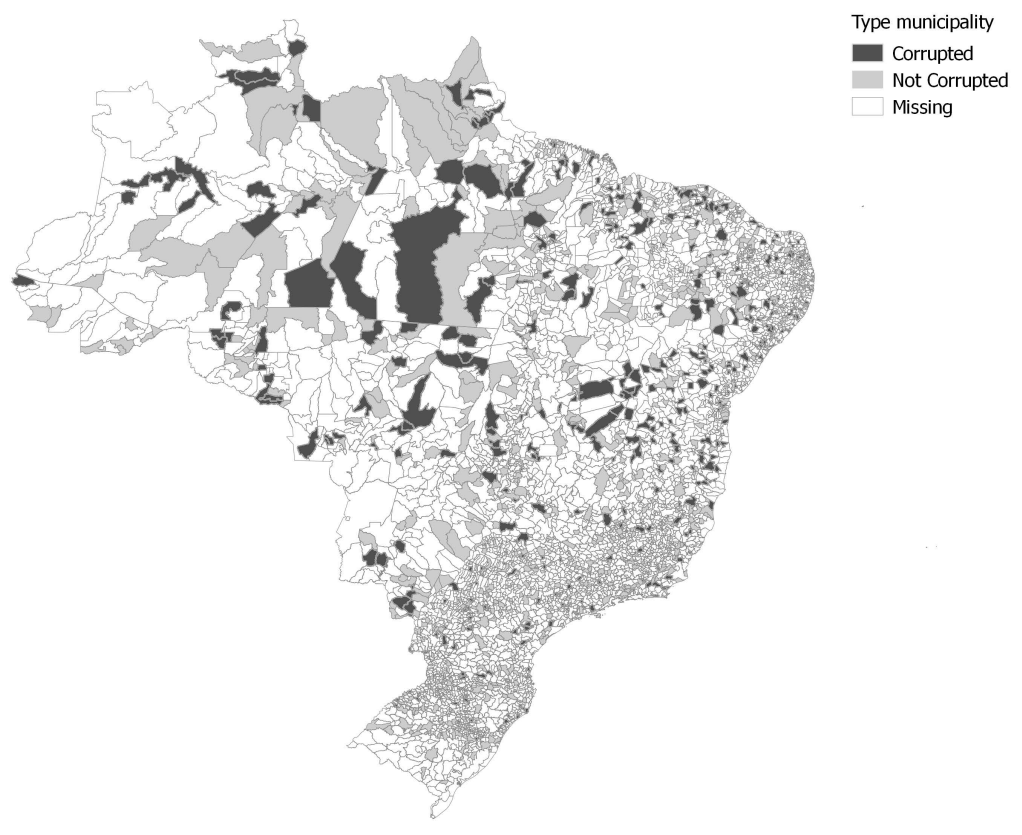

(b) Predicted Corruption

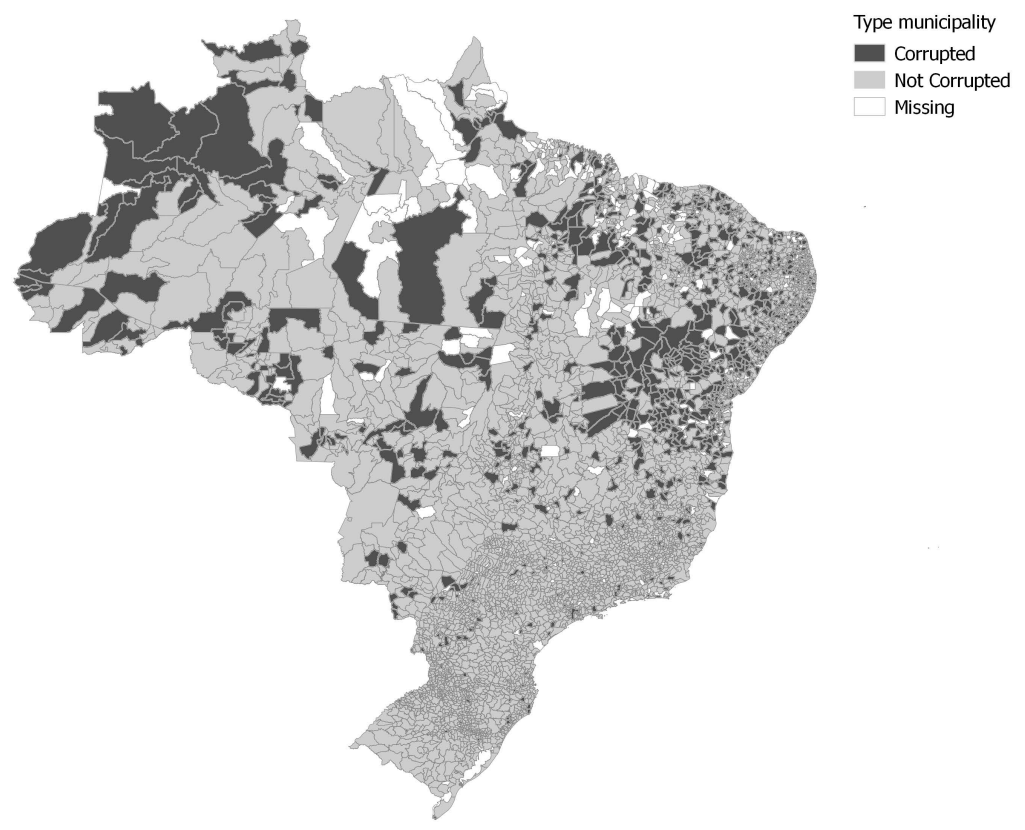

Notes: Municipalities in 2004. 


\subsection{Predicting Corruption for Non-Audited Municipalities}

An important aspect of our contribution is to provide a measure of corruption for all Brazilian municipalities and all years from 2001 to 2012. Therefore, we are able to analyze corruption in municipalities(-years) regardless of whether they have been audited. This is done by forming the predicted probability of corruption for all observations for which we have information about the budget. In Figure 3 we provide a visualization of the difference between the sample of only audited municipalities (on the top) and the sample of municipalities that we can analyze when using our predicted measure of corruption (on the bottom). The map illustrates quite clearly the additional information produced by the ML method.

As the audits are random, the distribution of (predicted) corruption should be the same in the audited and non-audited municipalities. To show this, we took budget data for years before any audits had been announced (2001 and 2002), and compared the corruption predictions for municipalities that were audited in 2003 to those that were not. They were not statistically different.

\section{Empirical Applications}

In this section we replicate, and extend, existing evidence from the literature on corruption in Brazil. This exercise has two purposes. On the one hand, it provides checks on the internal validity of our synthetic measure of corruption. On the other hand, we extend previous results by taking advantage of the larger sample of municipalities as well as of the time variation of the corruption measure.

\subsection{Revenue Shocks and Corruption}

As a first analysis we use the new synthetic measure of corruption to analyze the effect of revenue shocks on corruption, replicating and extending the findings by Brollo et al. (2013). The goal of that paper is to see whether a windfall of public revenues can lead to an increase in rent-seeking by the public administration (as measured by a subsequent surge in corruption). To address this issue, the study estimates the impact of federal transfers on the occurrence of corruption as detected by public audits, in the setting of Brazilian municipalities.

Brazilian municipalities receive transfers from the states and from the federal government. The latter type of transfers, the federal ones, Fundo de Participação dos 
Municipios (FPM), represent the most important source of municipal revenues (around $40 \%$ of the total budget). The allocation of these transfers relies on exogenous population thresholds, where municipalities in the same state and in a given population bracket receive the same amount of resources. In particular, municipalities are divided into population groups that determine the coefficients applied to divide federal revenues allocated to their state. Appendix Table A.3 shows these coefficients and the corresponding population bracket: following Brollo et al. (2013), we focus on the initial seven brackets and we restrict the sample to cities with population below $50,940,{ }^{9}$ representing about 90 percent of Brazilian municipalities. ${ }^{10}$

More precisely, the amount of revenues received by municipality $i$ in state $k$ follows the allocation mechanism:

$$
F P M_{i}^{k}=\frac{F P M_{k} \lambda_{i}}{\sum_{i \in k} \lambda_{i}}
$$

where $F P M_{k}$ is the total amount allocated in state $k$ and $\lambda_{i}$ is the municipality-specific coefficient, as shown in Table A.3. However population-level data does not perfectly predict the amount of FPM transfers received by Brazilian municipalities. This imperfect compliance is due to many factors (e.g. municipalities splitting, manipulation in population figures).

We replicate the dataset used by Brollo et al. (2013) on transfers and population. Our data cover the two mayoral terms, January 2001-December 2004 and January 2005December 2008. We generate theoretical transfers according to the methodology already discussed. ${ }^{11}$

There is one important difference in our dataset from Brollo et al. (2013). We generate a single dataset including the universe of Brazilian municipalities (in the population interval 6,793-50,940), whereas they only use data on the municipalities that were audited. The goal is to extend the analysis to the full sample of localities.

Table 3 shows the descriptive statistics by population bracket. It includes the value of the actual transfers - those actually received by cities - and the theoretical transfers -

\footnotetext{
${ }^{9}$ Furthermore, we follow the approach of Brollo et al. (2013) and we restrict the sample, for the sake of symmetry, to municipalities from 3,396 below the first threshold to 6,792 above the seventh threshold.

${ }^{10}$ These coefficients are set yearly by the federal court of audits (Tribunal de Contas União(TCU)), based on data by the Brazilian Institute of Geography and Statistics (IBGE).

${ }^{11}$ First, we recover transfer data from the website of the Brazilian National Treasury (Tesouro Nacional). Second, we obtain population data from the Brazilian Institute of Geography and Statistics (IBGE). We follow Brollo et al. (2013) in the treatment of these data.
} 
those computed according to the population thresholds. Brazilian municipalities in our sample receive, on average, \$3.4M BRL (about \$800K USD), while theoretical transfers are somewhat higher at $\$ 3.8 \mathrm{M}$ BRL (about $\$ 913 \mathrm{~K}$ USD).

The next column reports the summary statistics on our synthetic measure (ML predictions) for corruption, computed applying machine learning techniques to the rich budget dataset: in particular, we show the prediction for the narrow corruption measure (binary version). This prediction has been computed including in the ML specification the standardization, the set of missing dummies and the control for population. Table 3, columns 4, shows the descriptive statistics, by population bracket, of this measure of corruption used in the replication analysis. The average level of (predicted) corruption is around 0.5. Moreover the predicted corruption level does not seem to change significantly as we move to larger cities.

Table 3: Descriptive statistics

\begin{tabular}{|c|c|c|c|c|}
\hline \multirow[b]{2}{*}{$\begin{array}{c}\text { Population } \\
\qquad(1)\end{array}$} & \multicolumn{2}{|c|}{ FPM transfers } & \multirow{2}{*}{$\begin{array}{c}\text { Prediction: corruption } \\
\text { Narrow corruption } \\
(4)\end{array}$} & \multirow[b]{2}{*}{$\begin{array}{l}\mathrm{N} \\
(5)\end{array}$} \\
\hline & $\begin{array}{l}\text { Actual } \\
\text { transfers } \\
(2)\end{array}$ & $\begin{array}{c}\text { Theoretical } \\
\text { transfers } \\
(3)\end{array}$ & & \\
\hline $6,793-10,188$ & 19.764 & 21.352 & .395 & 1,505 \\
\hline $10,189-13,584$ & 25.717 & 28.934 & .519 & 1,120 \\
\hline $13,585-16,980$ & 32.039 & 36.553 & .549 & 848 \\
\hline $16,981-23,772$ & 38.55 & 44.342 & .574 & 1,133 \\
\hline $23,773-30,564$ & 44.424 & 51.481 & .547 & 665 \\
\hline $30,565-37,356$ & 51.139 & 58.618 & .526 & 400 \\
\hline $37,357-44,148$ & 57.335 & 66.647 & .491 & 263 \\
\hline $44,149-50,940$ & 62.829 & 72.897 & .516 & 159 \\
\hline Total & 33.558 & 38.171 & .505 & 6,093 \\
\hline
\end{tabular}

Finally, in terms of estimation strategy, we exploit the exogenous population thresholds, that determine the federal transfers, in order to study the causal impact of transfers on (predicted) corruption. The empirical model, which follows Brollo et al. (2013), is structured as a fuzzy regression discontinuity design methodology. We estimate the impact of theoretical transfers $\left(\hat{\tau}_{i}\right)$ on actual transfers $\left(\tau_{i}\right)$ and corruption $\left(y_{i}\right)$ under the assumption of continuity of the conditional regression functions of potential outcomes at the threshold. 
The first stage and reduced form are modeled by the respective equations:

$$
\begin{aligned}
& \tau_{i}=g\left(P_{i}\right)+\alpha_{\tau} \hat{\tau}_{i}+\delta_{t}+\gamma_{p}+u_{i} \\
& y_{i}=g\left(P_{i}\right)+\alpha_{y} \hat{\tau}_{i}+\delta_{t}+\gamma_{p}+\eta_{i}
\end{aligned}
$$

Where, $g(\cdot)$ is a high order polynomial in $P_{i}$ (the population estimate of city $i$ ), $\delta_{t}$ the term fixed effects, $\gamma_{p}$ the state fixed effects, and $u_{i}$ and $\eta_{i}$ are the errors terms, with standard errors clustered at the municipality level. The coefficients, $\alpha_{\tau}$ and $\alpha_{y}$ capture the effects of theoretical transfers on, respectively, actual transfers and (predicted) corruption. ${ }^{12}$

For the instrumental variable analysis, we estimate the second stage

$$
y_{i}=g\left(P_{i}\right)+\beta_{y} \tau_{i}+\delta_{t}+\gamma_{p}+\epsilon_{i}
$$

where theoretical transfers $\hat{\tau}_{i}$ are used as an instrument for actual transfers $\tau_{i}$ and all other terms are defined as above. The coefficient $\beta_{y}$ captures the causal effect of actual transfers on (predicted) corruption.

The main difference from Brollo et al. (2013) is that, while that paper focuses only on municipalities that receive an audit, our dataset allows us to test this hypothesis in a larger and more representative sample of cities. Therefore, our exercise is also providing a test for the external validity of the results by Brollo and coauthors. Nevertheless, for the sake of brevity we only replicate the analysis on the overall effect, omitting the threshold-specific analysis.

Table 4, Panel A, shows the results for the first stage (models 1), using our synthetic measure of corruption. In column 1, we only include cities that received an audit - this is the same sample used by Brollo et al. (2013). We replicate their findings: Column 1 shows that theoretical transfers positively and significantly affect actual transfers. In column 2, we conduct the analysis with the entire set of cities. The results are similar in terms of precision, and the coefficient is very similar. Finally, in column 3, we exclude cities that have been audited in order to provide a fully out-of-sample validation. Also in this case, coefficients are similar in terms of precision and direction, but smaller in magnitude.

\footnotetext{
${ }^{12}$ See Brollo et al. (2013) for a detailed discussion and testing of the econometric assumptions in this setting.
} 
Table 4: Replication Brollo et al (2013)

\begin{tabular}{lccc}
\hline & $\begin{array}{c}\text { Audited cities } \\
(1)\end{array}$ & $\begin{array}{c}\text { All cities } \\
(2)\end{array}$ & $\begin{array}{c}\text { Cities non-audited } \\
(3)\end{array}$ \\
\hline Panel A. First Stage & & & \\
Theoretical transfers & $\begin{array}{c}0.680^{* * *} \\
(0.021)\end{array}$ & $\begin{array}{c}0.687^{* * *} \\
(0.022)\end{array}$ & $\begin{array}{c}0.700^{* * *} \\
(0.023)\end{array}$ \\
Panel B. Reduced Form & & & \\
Actual transfers & $0.00526^{* *}$ & $0.00370^{* * *}$ & $0.00294^{* * *}$ \\
& $(0.00264)$ & $(0.001)$ & $(0.001)$ \\
Panel C. 2SLS & & & $0.00660^{* * *}$ \\
Actual transfers & $0.00862^{* *}$ & $0.00731^{* * *}$ & $(0.001)$ \\
& $(0.004)$ & $(0.001)$ & 4693 \\
\hline N. Observations & 1115 & 5809 & \\
\hline
\end{tabular}

Notes: Effects of FPM transfers on (predicted) corruption measures. Panel A reports the estimates of the first-stage analysis, the dependent variable is actual transfers. Panel B reports the estimates of reduced form analysis, the dependent variable is predicted corruption. Panel $\mathrm{C}$ reports the estimates of the 2sls estimates, the dependent variable is predicted corruption and actual transfers is instrumented with theoretical transfers. Column headings indicate the sample of municipalities included. All regressions controls for a third-order polynomial in normalized population size, term dummies, and macro-region dummies as in equation (7). Robust standard errors clustered at the municipal level are in parentheses: ${ }^{*} p<0.10,{ }^{* *} p<0.05,{ }^{* * *}$ $p<0.01$. 
Second, Panel B of Table 4 shows the results for the reduced form (models 2). We can see that theoretical transfers positively and significantly affect (predicted) corruption for the sample of audited cities (column 1), for all cities (column 2) and for non-audited cities (column 3). The magnitude of the coefficient ranges between $21 \%$ and $37.6 \%$ the size of the one estimated by Brollo et al. (2013), which could be due to measurement error introduced by the machine learning prediction.

Finally, Panel C of Table 4 shows the corresponding two-stage-least-squares estimates for the three different samples (models 3). Again, the main findings by Brollo et al. (2013) are confirmed, following the same patterns as the reduced form. The effect is always positive and significant, but the magnitude of coefficients change among columns. The analysis on audited cities (column 1) shows the largest coefficients, which is around $39.2 \%$ the size of those estimated by Brollo and coauthors. The estimates presented in the others columns show coefficients with smaller magnitudes.

Overall, these results support the internal validity of our synthetic measures of corruption and provide additional evidence on the external validity of findings by Brollo et al. (2013).

\subsection{Effect of Audits on Corruption}

Our next empirical analysis is to use our data to analyze the effect of auditing on corruption in an event study framework. Avis et al. (2018) analyze this question using the set of Brazilian municipalities that were (by random draw) audited twice. With a crosssectional analysis, they find that corruption tends to be lower the second time around. Bobonis et al. (2016) study a similar research question in Puerto Rican municipalities. The authors focus on (non random) audit of municipal accounts, finding that audits do not persistently reduce corruption in that case. In particular, they find that audits released right before elections diminish corruption levels, but this effect disappears by the next electoral term. Therefore the effect of audits on corruption seems sensitive to the institutional context and, importantly, there are not evidence about the dynamic effect of audits when these are unexpected by local authorities.

With our new measure of predicted corruption we can overcome data limitations in Avis et al. (2018) and provide a larger set of results. First, because of the longitudinal nature of our dataset we can capture dynamic effects. Moreover, we can condition our estimates on pre-audit levels of corruption. Finally, our effects are identified by a relatively larger sample of municipalities that got the audit at least once. 
To get at these issues, we analyze the effect of audits on corruption using our budgetbased prediction measure. Using the annual prediction $y_{i s t}$ in municipality $i$ of state $s$ at year $t$, we take a standard event study approach and estimate the within-municipality impact effects of a (randomly assigned) audit. Let $D_{i s t}^{k}$ be a dummy variable for $k$ years before and after an audit. We estimate

$$
y_{i s t}=\sum_{k=-2, k \neq 0}^{5} \beta_{k} D_{i s t}^{k}+\delta_{i}+\lambda_{i} \cdot t+\gamma_{s t}+X_{i s t}^{\prime} \phi+\epsilon_{i s t}
$$

where we have municipality fixed effects $\delta_{i}$, municipality trends $\lambda_{i} \cdot t$, state-year fixed effects $\gamma_{s t}$, and other controls $X_{i s t}$, which in particular includes dummy variables indicating periods distant from when the audit took place. Because $k \neq 0$ (the year the audit is announced), the $\beta_{k}$ estimate the dynamic effects relative to the year the audit took place. The identifying assumption hings on the randomness in the timing in which municipalities are selected into the audit program - similarly to most of the related literature focusing on this anti-corruption policy. We cluster standard errors by state. The sample includes 1,438 municipalities, those that have received an audit in the time span in analysis. ${ }^{13}$

The estimates for Equation (4) are reported in Figure 4, top panel. We can see that in the years after the audit is announced $(k=1)$, there is a sharp and statistically significant drop in predicted corruption. This persists over the subsequent years. Meanwhile, as expected given the random assignment due to the lottery, there is no statistically significant effect in the pre-announcement years.

In the bottom panel of Figure 4, we report effects for the subsets of audits that find clear corruption (left panel) and those that do not find corruption at all (right panel). These trends look quite different. When there is corruption (left panel), there is a much larger negative effect (around $-20 \%$, compared to $-5 \%$ for pooling all audits). In addition it continues to decrease in the subsequent years after the audit results were issued, suggesting additional effects due to enforcement and/or politics. In contrast,

\footnotetext{
${ }^{13}$ It is worth mentioning that we exclude from the sample the municipality-year observations that were part of the training set. We apply such restriction to account for the fact that our treatment (periods after the audit) is also identifying observations that never got into the training sample. In other words, we exclude potential concerns about systematic differences in prediction accuracy between observations in the training set and in the test set, that might confound the treatment status. Nevertheless, results are similar also when including all observations in the sample.
} 
Figure 4: Dynamic Effect of Audits on Fiscal Corruption
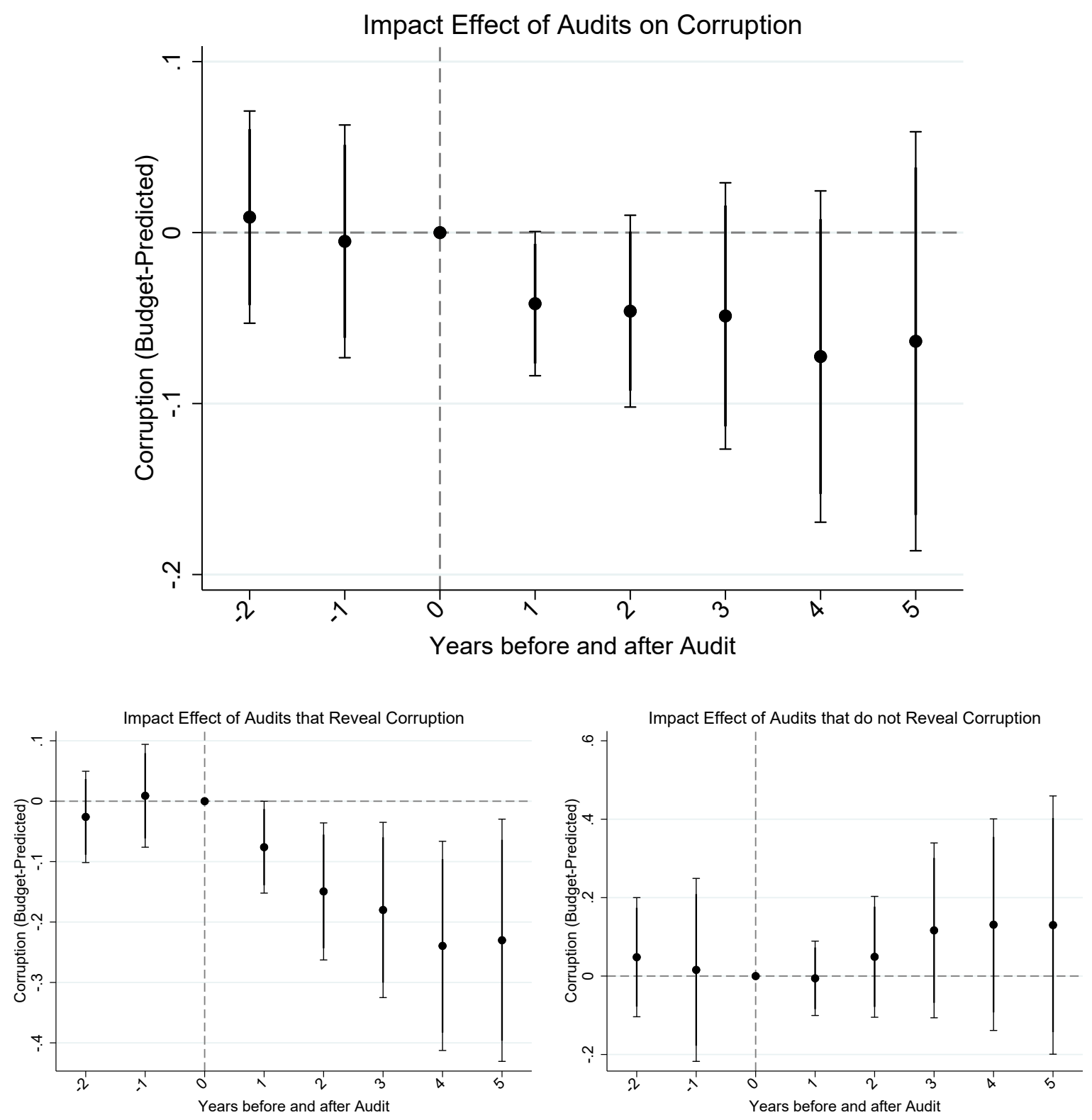

Notes: Event study estimates for dynamic effect of audits on budget-predicted corruption. Error spikes give $95 \%$ confidence intervals, with standard error clustered by state. Top panel: all audits; bottom-left panel: audits that found corruption; bottom-right panel: audits that did not find corruption. 
when the audit does not find any corruption or irregularities (right panel), there is no effect on corruption and all the coefficients are zeros. ${ }^{14}$

\subsection{Spillover Effects of Audits on Neighboring Municipalities}

As an additional analysis, we raise the issue of whether the disciplinary effects of an audit may spill-over geographically to neighboring cities. Avis et al. (2018) also analyze this issue in the Brazilian setting, using the small number of neighboring municipalities that have both been audited. They find that an audit reduces corruption in neighboring cities but the result is conditional on local media being present. Along the same line, Galletta (2017) studies the Italian setting and finds that when a city council is dismissed (because of the presence of mafia-connected officials), neighboring municipalities display reduction in misconduct. Our innovation on this literature is to evaluate the dynamics of the effects over time and to observe how the effect changes depending on the audit's outcome.

The empirical strategy is the same as above, but focusing on cities that have not been audited but that have at least one neighboring municipality that has been audited ${ }^{15}$. We estimate Equation 4 for this set of municipalities, but where $D_{i s t}^{k}$ now indicates a dummy variable for $k$ years before and after the neighbor had an audit. The other elements are the same - municipality fixed effects, municipality trends, state-year fixed effects, and clustering by state.

Figure 5, top panel, reports the results for the spillover analysis. An audit leads to a reduction in predicted corruption in neighboring cities; the effect grows over time but is not statistically different from zero. ${ }^{16}$

Next, as we did above we split the sample conditioning on the outcome of the audit. In Figure 5, bottom panel - left sub-plot, we show the effect for cities having at least

\footnotetext{
${ }^{14}$ We also test for the channel of political accountability. We check whether the effect of the audit is stronger when the mayor has career or re-election incentives: i.e., whether she is term-limited or not, whether she will run again in the following elections, or whether the electoral competition is high (low margin of victory). Moreover, we check whether these results are amplified by the presence of local media, using as proxy the presence of a local radio. In both cases we did not find significant heterogeneous results, suggesting that political accountability and the presence of the media do not amplify the disciplinary effect of the audits.

${ }^{15}$ The sample includes 3,145 municipalities with at least one neighbor that received the audit in the time span in analysis. Most of the times -2,073 municipalities- the audit finds some form of corruption (according to the definition of narrow corruption).

${ }^{16}$ This insignificant effect is coherent with Avis et al. (2018). Indeed, they find a significant spillover effect only when conditioning on the presence of some media outlet such as radio or TV.
} 
Figure 5: Spillover Effect of Neighboring Audits on Fiscal Corruption
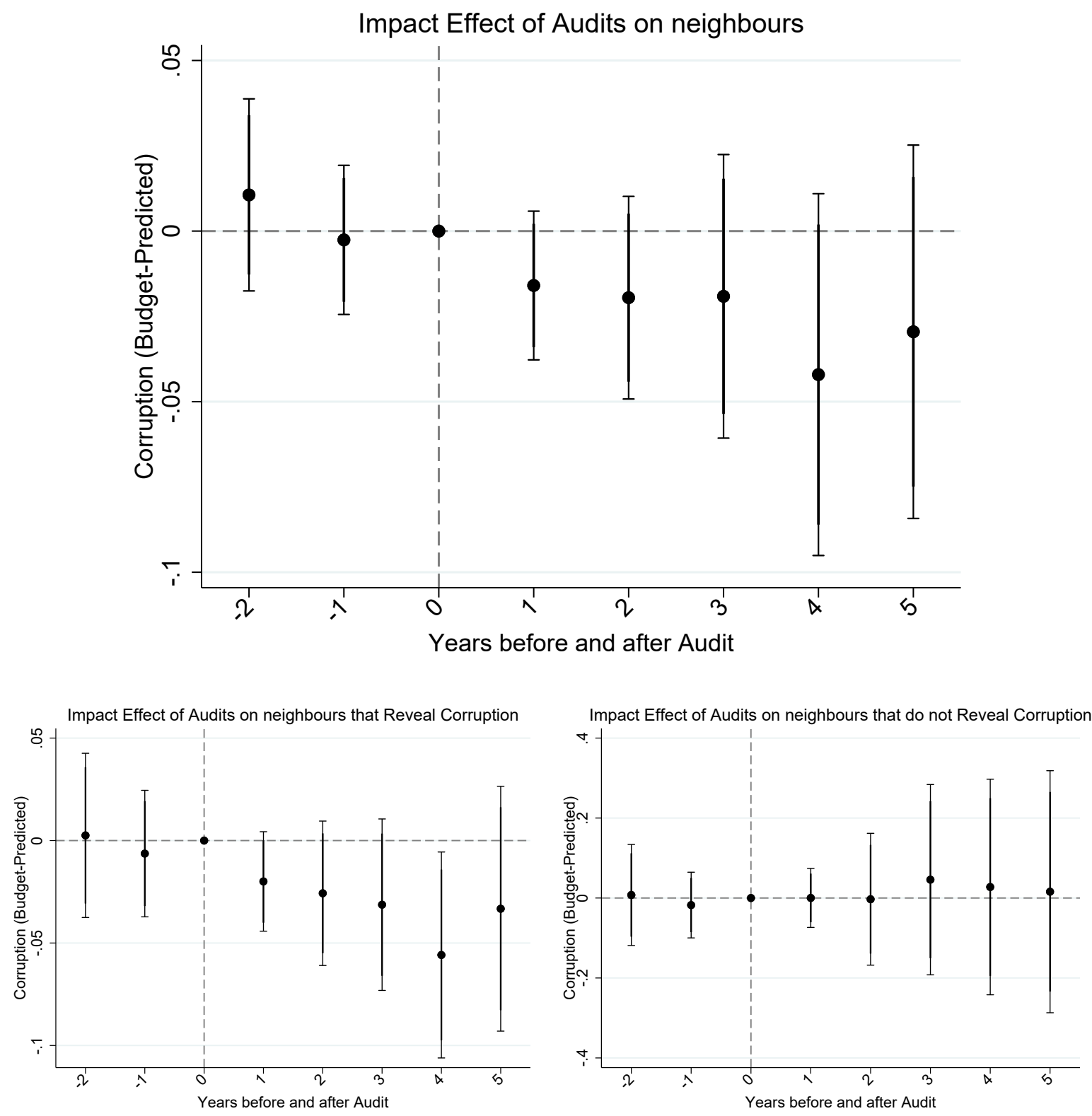

Notes. Event study estimates for dynamic effect of audits on budget-predicted corruption. Error spikes give $95 \%$ confidence intervals, with standard error clustered by state. Top panel: all audits; bottom-left panel: audits that found corruption; bottom-right panel: audits that did not find corruption. 
one corrupted neighboring municipality, according to the audit. In this sample the audit leads to a negative and significant reduction in fiscal corruption, between $2 \%$ and $6 \%$. Instead, we do not observe any effect for cities whose neighbors were not found corrupted by the audit (bottom panel - right sub-plot). Appendix Figure A.1 provides additional evidence on that dynamic: left sub-figure shows the impact for cities that have many corrupted neighbors, i.e. more than half of the audited neighbors were found corrupted. Also in this case the audit reduces corruption and the effect is stronger and more precisely estimated than in the previous cases, while we do not observe any spillover effects for the other group (right sub-plot).

\subsection{Discussion}

These results provide new evidence about how audits influence corrupt activities in Brazilian municipalities. The fact that there is no effect for municipalities with no corruption suggests that our main effect is not just due to accounting responses - even in places without corruption, they would likely change accounts to reduce any factors that are associated with corruption. Therefore, the impact effect likely consists of reductions in corruption-related activity, and not just accounting changes. The fact that there is a much larger effect after audits when corruption is found is consistent with a significant disciplining effect.

The spillover effect on neighboring municipalities is especially interesting. The fact that there is an immediate decrease in fiscal corruption is consistent with a behavioral response. If it was a learning response through the political process, one would expect a more gradual effect. This could mean that the neighboring municipalities are overestimating their subjective probability of subsequent audit. Alternatively, the changes in the budget might be due to a reassessment of the neighboring municipalities beliefs about the potential punishment of an illegal conduct.

Additional insights like these were not possible to obtain with the standard methods used in the previous literature. The number of multiple audits is too small, and the crosssectional data too sparse, to analyze the rich comparative dynamics that we can do with our ML-predicted panel data. Therefore the information on corruption produced by machine learning could be useful not just for policymakers, but also for social scientists interested in answering new research questions. 


\section{Conclusion}

This paper has shown that corruption in local governments can be reliably detected, predicted, and measured using public budget accounts data. We have shown that the resulting synthetic measurements can then be used in downstream empirical analysis, as we can produce the same empirical results using corruption predictions in municipalities that were never audited. Moreover, we can show that the expanded allows us to ask old questions in new ways, or to ask entirely new questions.

This research adds to the emerging literature using machine learning and other tools from data science to explore new datasets and questions (Athey, 2018). Our method of detecting corruption has the potential to substantially expand the stock of datasets available for economists studying development, political economy, and public finance. Within Brazil, researchers will no longer be constrained to the relatively small set of municipalities that were audited. Outside of Brazil, the method could in principle be applied in any context with ground-truth labels for corruption. Something that can and should be explored is whether the corruption predictions produced in Brazil could be valid for other countries and settings. 


\section{References}

Ash, E., M. Morelli, and R. Van Weelden (2017). Elections and divisiveness: Theory and evidence. The Journal of Politics 79(4), 1268-1285.

Athey, S. (2018). The impact of machine learning on economics. In The economics of artificial intelligence: An agenda. University of Chicago Press.

Avis, E., C. Ferraz, and F. Finan (2018). Do government audits reduce corruption? estimating the impacts of exposing corrupt politicians. Journal of Political Economy 126(5), 1912-1964.

Bandiera, O., A. Prat, S. Hansen, and R. Sadun (2020). Ceo behavior and firm performance. Journal of Political Economy 0(0), 000-000.

Becker, G. S. (1968). Crime and punishment: An economic approach. Journal of Political Economy 76(2), 169-217.

Bobonis, G. J., L. R. Cámara Fuertes, and R. Schwabe (2016). Monitoring corruptible politicians. American Economic Review 106(8), 2371-2405.

Brollo, F., T. Nannicini, R. Perotti, and G. Tabellini (2013). The political resource curse. American Economic Review 103(5), 1759-96.

Cavalcanti, F., G. Daniele, and S. Galletta (2018). Popularity shocks and political selection. Journal of Public Economics 165, 201-216.

Chen, T. and C. Guestrin (2016). Xgboost: A scalable tree boosting system. In Proceedings of the 22nd acm sigkdd international conference on knowledge discovery and data mining, pp. 785-794.

Cheol, L. and J. Mikesell (2018). The impact of public officials' corruption on the size and allocation of u.s. state spending. Public Administration Review, 346-359.

Chong, A., A. L. De La O, D. Karlan, and L. Wantchekon (2015). Does corruption information inspire the fight or quash the hope? a field experiment in mexico on voter turnout, choice, and party identification. The Journal of Politics r7(1), 55-71.

Colonnelli, E., J. A. Gallego, and M. Prem (2019). What predicts corruption? Available at SSRN 3330651.

Conley, T. G. and F. Decarolis (2016). Detecting bidders groups in collusive auctions. American Economic Journal: Microeconomics 8(2), 1-38.

Coviello, D. and S. Gagliarducci (2017). Tenure in office and public procurement. American Economic Journal: Economic Policy 9(3), 59-105. 
Daniele, G. and T. Giommoni (2020). Corruption under austerity. BAFFI CAREFIN Centre Research Paper No. 2020-131.

De Angelis, I., G. de Blasio, and L. Rizzica (2018). On the unintended effects of public transfers: evidence from eu funding to southern italy. Temi di discussione (Economic working papers) 1180, Bank of Italy, Economic Research and International Relations Area.

Djankov, S., R. La Porta, F. Lopez-de Silanes, and A. Shleifer (2003). Courts. The Quarterly Journal of Economics 118(2), 453-517.

Draca, M. and C. Schwarz (2019). How polarized are citizens? measuring ideology from the ground-up. Working papers, University of Warwick.

Ferraz, C. and F. Finan (2008). Exposing corrupt politicians: The effects of Brazil's publicly released audits on electoral outcomes. The Quarterly Journal of Economics 123(2), 703-745.

Ferraz, C. and F. Finan (2011). Electoral accountability and corruption: Evidence from the audits of local governments. The American Economic Review 101(4), 1274-1311.

Friedman, J. H. (2001). Greedy function approximation: a gradient boosting machine. Annals of statistics, 1189-1232.

Gallego, J., G. Rivero, J. D. Martínez, et al. (2018). Preventing rather than punishing: An early warning model of malfeasance in public procurement. Technical report.

Galletta, S. (2017). Law enforcement, municipal budgets and spillover effects: Evidence from a quasi-experiment in italy. Journal of Urban Economics 101, 90 - 105.

Gentzkow, M. and J. M. Shapiro (2010). What drives media slant? evidence from us daily newspapers. Econometrica 78(1), 35-71.

Gentzkow, M., J. M. Shapiro, and M. Taddy (2019). Measuring group differences in high-dimensional choices: Method and application to congressional speech. Econometrica $87(4), 1307-1340$.

Hessami, Z. (2014). Political corruption, public procurement, and budget composition: Theory and evidence from oecd countries. European Journal of Political Economy 34 (C), 372-389.

Kleinberg, J., J. Ludwig, S. Mullainathan, and Z. Obermeyer (2015). Prediction policy problems. American Economic Review 105(5), 491-95.

Lagaras, S., J. Ponticelli, and M. Tsoutsoura (2017). Caught with the hand in the cookie jar: Firm growth and labor reallocation after exposure of corrupt practices. 
López-Iturriaga, F. J. and I. P. Sanz (2018). Predicting public corruption with neural networks: An analysis of spanish provinces. Social Indicators Research 140(3), 975998.

Mauro, P. (1998). Corruption and the composition of government expenditure. Journal of Public economics 69(2), 263-279.

Morris, S. D. and J. L. Klesner (2010). Corruption and trust: Theoretical considerations and evidence from mexico. Comparative Political Studies 43(10), 1258-1285.

Olken, B. A. (2007). Monitoring corruption: evidence from a field experiment in indonesia. Journal of political Economy 115(2), 200-249.

Tanzi, V. and H. Davoodi (1998). Corruption, public investment, and growth. In The welfare state, public investment, and growth, pp. 41-60. Springer.

Winters, M. S. and R. Weitz-Shapiro (2013). Lacking information or condoning corruption: When do voters support corrupt politicians? Comparative Politics 45(4), $418-436$.

Zamboni, Y. and S. Litschig (2018). Audit risk and rent extraction: Evidence from a randomized evaluation in brazil. Journal of Development Economics 134, 133 - 149. 


\section{A. Appendix}

\section{A.1. Other Figures and Tables}

Figure A.1: Effect of Audits of neighbors Corruption - Cities with more than $50 \%$ corrupted neighbors
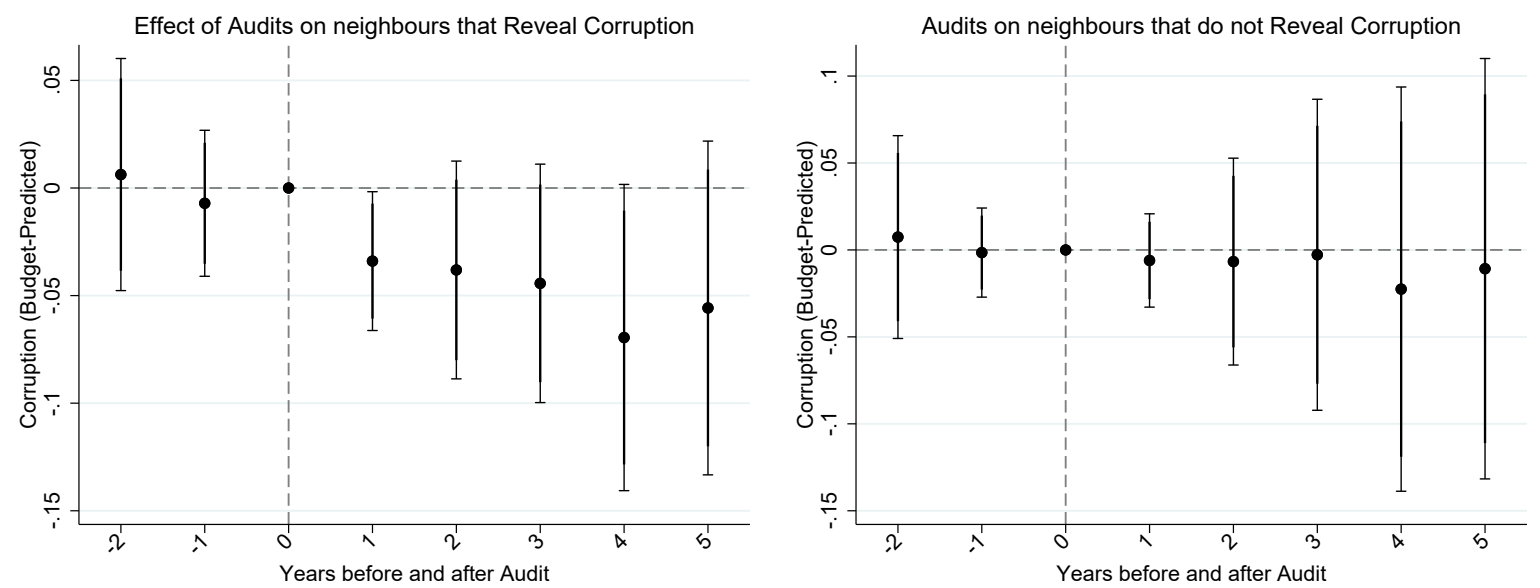

Notes. Event study estimates for dynamic effect of audits on budget-predicted corruption. Error spikes give $95 \%$ confidence intervals, with standard error clustered by state. 
Table A.1: Balance sheets components

\begin{tabular}{ccccc|c}
\hline & \multicolumn{5}{c}{ Number of categories } \\
\cline { 2 - 5 } Year & Active & Passive & Expenditure & Revenue & Total \\
\hline 2001 & 56 & 46 & 43 & 52 & 197 \\
2002 & 56 & 46 & 101 & 90 & 293 \\
2003 & 57 & 48 & 100 & 90 & 295 \\
2004 & 59 & 49 & 295 & 146 & 549 \\
2005 & 63 & 52 & 298 & 151 & 564 \\
2006 & 63 & 52 & 301 & 155 & 571 \\
2007 & 64 & 52 & 309 & 170 & 595 \\
2008 & 64 & 52 & 310 & 170 & 596 \\
2009 & 80 & 57 & 331 & 198 & 666 \\
2010 & 88 & 69 & 334 & 219 & 710 \\
2011 & 89 & 69 & 335 & 219 & 712 \\
2012 & 89 & 69 & 334 & 219 & 711 \\
\hline
\end{tabular}

Table A.2: Confusion Matrix for Binary Prediction Tasks

\section{Corruption OLS}

\section{Prediction}

$\begin{array}{lcc}\text { Truth } & \text { Not Corrupt } & \text { Corrupt } \\ \text { Not Corrupt } & 548 & 143 \\ \text { Corrupt } & 348 & 173\end{array}$


Table A.3: Population thresholds for Inter-Government Transfers

\begin{tabular}{lc}
\hline \hline Population interval & FPM coefficient \\
\hline Below 10,189 & 0.6 \\
$10,189-13,584$ & 0.8 \\
$13,585-16,980$ & 1 \\
$16,981-23,772$ & 1.2 \\
$23,773-30,564$ & 1.4 \\
$30,565-37,356$ & 1.6 \\
$37,357-44,148$ & 1.8 \\
$44,149-50,940$ & 2 \\
Above 50,940 & from 2.2 to 4 \\
\hline \hline
\end{tabular}

Notes: These coefficients have been introduced by Decreto-lei n. 1,881, 27 august 1981. 